\title{
Operating experiences with an advanced fabric energy storage system in Australia
}

R.J. Fuller (Built Environment Research Group School of Architecture and Building Waterfront Campus, Deakin University, Australia)

\section{ABSTRACT}

Despite their proven track record in the cold climate countries of northern Europe, there are no reports in the research literature of experiences using advanced fabric energy storage (FES) systems in countries where cooling rather than heating is the main priority. This paper reports some of the experiences with the first known advanced FES system in Australia made over the first full calendar year of operation. It is located in a threestorey building on a university campus in Victoria and has been in operation since mid-2002. Temperature, energy use and operational mode data were recorded during 2003. Airflow measurements through the FES have been made in five areas of the building. On-going operating problems still exist with the system and this has prevented a conclusive evaluation of its suitability for the southern Australian climate.

Keywords: fabric energy storage; ventilation; energy use; cooling; heating.

\section{INTRODUCTION}

Advanced fabric energy storage (FES) systems offer the opportunity to reduce annual and peak energy use in commercial buildings. Developed in Sweden, advanced FES systems have been used successfully in low energy buildings in several European countries. The hollow-core concrete panels are actively incorporated into the heating-cooling system and benefits can be achieved by exploiting the thermal capacitance of the concrete. As ventilation air is passed through the panels, its temperature may be moderated by the concrete mass, if this is at an advantageous temperature. At night, energy absorbed by the FES during the day from occupants, equipment and solar input can be removed by flushing with cooler ambient air, providing a source of 'coolth' for the next day. The parameters affecting the performance of an FES system include the air flow rate and its control, the path length and the panel thickness.

The performance of these systems in cold-climate countries has been extensively reported. Two monitored Swedish buildings, for example, used approximately $50 \mathrm{kWh} \mathrm{m}^{-2}$ for heating and ventilation (Winwood et al., 1997a). In the UK, the first FES building consumed about $85 \mathrm{kWh} \mathrm{m}^{-2}$ but subsequent buildings have bettered the Swedish figure (Winwood, 1997). In terms of gas and electricity consumption for ventilation, the Elizabeth Fry building at the University of East Anglia was ranked $1^{\text {st }}$ and $8^{\text {th }}$ respectively in a study of 18 exemplar buildings (Cohen and Bunn, 2001) and its total $\mathrm{CO}_{2}$ emissions were just over half the benchmark for academic buildings in the UK (Probe, 1998). Some of the problems that have been encountered have also been reported e.g. Winwood (1997).
The use and performance of advanced FES use and performance in warm-climate countries is much less well documented. In recent years, advanced FES systems have received some attention from designers and architects in Australia and at least two buildings have been constructed using this technology. The intent of this paper is to document the first year of operational experience (positive and negative) with one of those FES systems for the benefit of other users. The paper begins with a description of the building, its heating and cooling system and the measurements made. This is followed by some analysis of the performance and operation of the FES based on the data collected.

\section{BUILDING DESCRIPTION}

Building $T$ is a three-storey building on the Burwood Campus of Deakin University, providing offices, laboratories and computer rooms. These spaces are located on either side of a central atrium (Fig. 1). The total floor area is $2860 \mathrm{~m}^{2}$ and each floor of the building is divided into 'pods', each of which is approximately $74 \mathrm{~m}^{2}$ in area. Internal partitions, full and threequarter height, have been installed in many pods to create individual offices. The floors are carpeted but the ceilings are exposed to maximise heat transfer. The east and west walls of the building are constructed from insulated concrete panels. Other features of the building (shading screens, efficient lighting and day-lighting) reduce its energy consumption. 


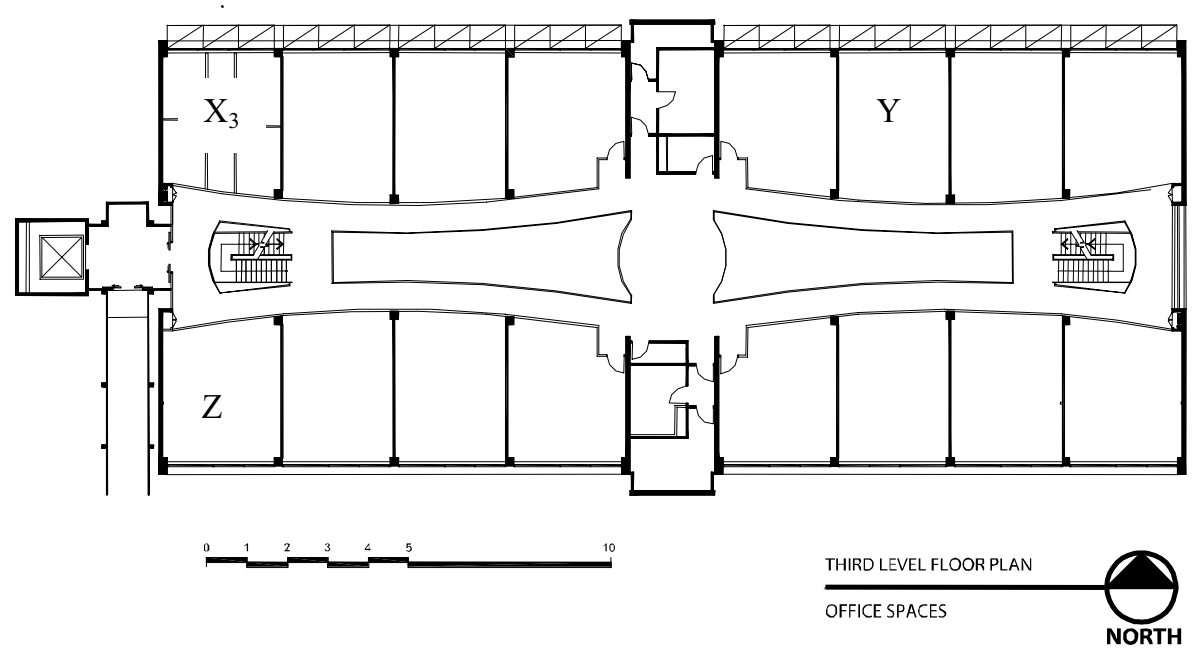

Figure 1: Upper floor plan in Building T

\section{HEATING, COOLING and VENTILATION SYSTEMS}

The building is not air-conditioned, but if the space temperature falls outside the range of $20-28^{\circ} \mathrm{C}$ heating and cooling is provided by a $220 \mathrm{~kW}$ boiler and a $150 \mathrm{~kW}$ chiller respectively. Two air handling units (AHUs) are primarily responsible for the distribution of tempered air to the three floors of the building. Outside air can be drawn in through the AHUs via wall-mounted external louvres. Fan coil units (FCUs) in the bulkheads on each level of the atrium, distribute air through the FES system. Air entering may be also be reheated at any FCU by a hot water coil. Apart from opening windows and operating ceiling sweep fans, the occupants have no control over their thermal environment. Two large fans at the top of the atrium assist in ventilation and also function as smoke spill fans.

The building has eight modes of operation, depending on external and internal conditions (Table 1). The temperatures of the outside, internal and atrium air are the prime variables, but the temperature of the concrete panels is also used as an input to the control system to maintain the FES within a certain temperature range.

\begin{tabular}{|c|l|c|c|c|c|}
\cline { 3 - 6 } \multicolumn{2}{c|}{} & \multicolumn{4}{c|}{ Conditions } \\
\hline \multirow{2}{*}{ Mode } & \multicolumn{1}{|c|}{ Description } & $\begin{array}{c}\text { Outside Air } \\
\text { Temp }\left({ }^{\circ} \mathrm{C}\right)\end{array}$ & $\begin{array}{c}\text { Internal Air } \\
\text { Temp }\left({ }^{\circ} \mathrm{C}\right)\end{array}$ & $\begin{array}{c}\text { Atrium Air } \\
\text { Temp }\left({ }^{\circ} \mathrm{C}\right)\end{array}$ & $\begin{array}{c}\text { Panel } \\
\text { Temp }\left({ }^{\circ} \mathrm{C}\right)\end{array}$ \\
\hline 1 & Boiler Heating & $\leq 15$ & $<20$ & n.a. & n.a. \\
\hline 2 & Atrium Heating & $\leq 18$ & $<20$ & $>20$ & n.a. \\
\hline 3 & Idling & $18-26$ & $20-28$ & n.a & n.a. \\
\hline 4 & Day Cooling & $>26$ & n.a & n.a & n.a. \\
\hline 5 & Night Cooling & $\begin{array}{c}>20 \\
\text { after } 10 \mathrm{pm}\end{array}$ & n.a. & n.a. & $>20$ \\
\hline 6 & Night Purge & n.a. & $\begin{array}{c}\text { outside air }+ \\
2\end{array}$ & n.a. & $>20$ \\
\hline 7 & Warm up & n.a. & n.a. & n.a. & $<18$ \\
\hline 8 & Shut down & n.a. & n.a. & n.a. & n.a. \\
\hline
\end{tabular}

(n.a. - not applicable)

Table 1: Modes and governing conditions for Building T

The operation of the various mechanical components in each mode is given in Table 2 . The building is designated as "naturally ventilated" and relies on fresh air entering through the windows (Mode 3) and the AHU louvres (Mode 6). Stale air is exhausted out of the building by the operation of the exhaust fans in the top of the atrium. In all other modes, the atrium is regarded as a reservoir of fresh air and internal air is circulated through the FES, relying on general airflow through any open windows and doors in the atrium for fresh air. There are some fully conditioned spaces containing the main computers and laboratory equipment. These spaces, representing $3.5 \%$ of the building floor area, use two 6kW packaged air conditioners. 


\begin{tabular}{|c|c|c|c|c|c|}
\hline Mode & AHU Fan & FCU Fan & Chiller & Boiler & Exhaust \\
\hline 1 & on & on & off & modulated & off \\
\hline $\mathbf{2}$ & off & on & off & modulated & off \\
\hline $\mathbf{3}$ & off & off & off & off & modulated \\
\hline $\mathbf{4}$ & on & on & modulated & off & off \\
\hline $\mathbf{5}$ & on & on & on & off & off \\
\hline $\mathbf{6}$ & on & on & off & off & $50 \%$ \\
\hline $\mathbf{7}$ & on & on & off & modulated & off \\
\hline $\mathbf{8}$ & off & off & off & off & off \\
\hline
\end{tabular}

Table 2: Modes and states of main devices in conditioning system in Building T

\section{FES SYSTEM}

A typical concrete panel used in the building is approximately $7.0 \mathrm{~m}$ long and $1.2 \mathrm{~m}$ wide. It is $0.205 \mathrm{~m}$ thick and contains five $155 \mathrm{~mm}$ diameter ducts. Six of these panels, lying in an eastwest direction, form the ceiling of each pod, the ends of the panels being inserted in supply manifolds (Fig. 2). When the FCU fans are operating, air is forced down the length of the first duct of each panel from a supply manifold and then transferred to the adjacent duct via a short $100 \mathrm{~mm}$ cross duct formed in the dividing concrete web. The air then flows back in the reverse direction in the adjacent duct. This flow pattern continues and the air goes up and down through the panel in a serpentine fashion. The air exits into the room space below the panels via three outlet holes formed in the lower panel surface at various locations. The average air velocity through the ducts is approximately $0.47 \mathrm{~m} \mathrm{~s}^{-1}$. There are no diffusers or flow adjusters fitted at the outlet holes. Although annular diffusers were originally specified, no local supplier could be located and imported units were considered to be too expensive. The mechanical design consultants apparently did not consider that flow adjusters were necessary to achieve uniform flow distribution. Path lengths between the supply manifold and first hole, first and second holes, and second and third holes are 5.6, 8.6 and $9.1 \mathrm{~m}$ respectively. This arrangement differs from systems installed in Europe, where one outlet hole for a single panel is normally used. This FES system also differs from many European systems because no heat recovery units have been installed.

\section{TEMPERATURE MEASUREMENTS}

The first period of monitoring, (November 2002-March 2003) focussed on Pod $Y$ (Fig. 1). The pod consists of three offices (A, $B$ and $D$ ) with full-height partitions and an adjacent open space (C) (Fig. 2).

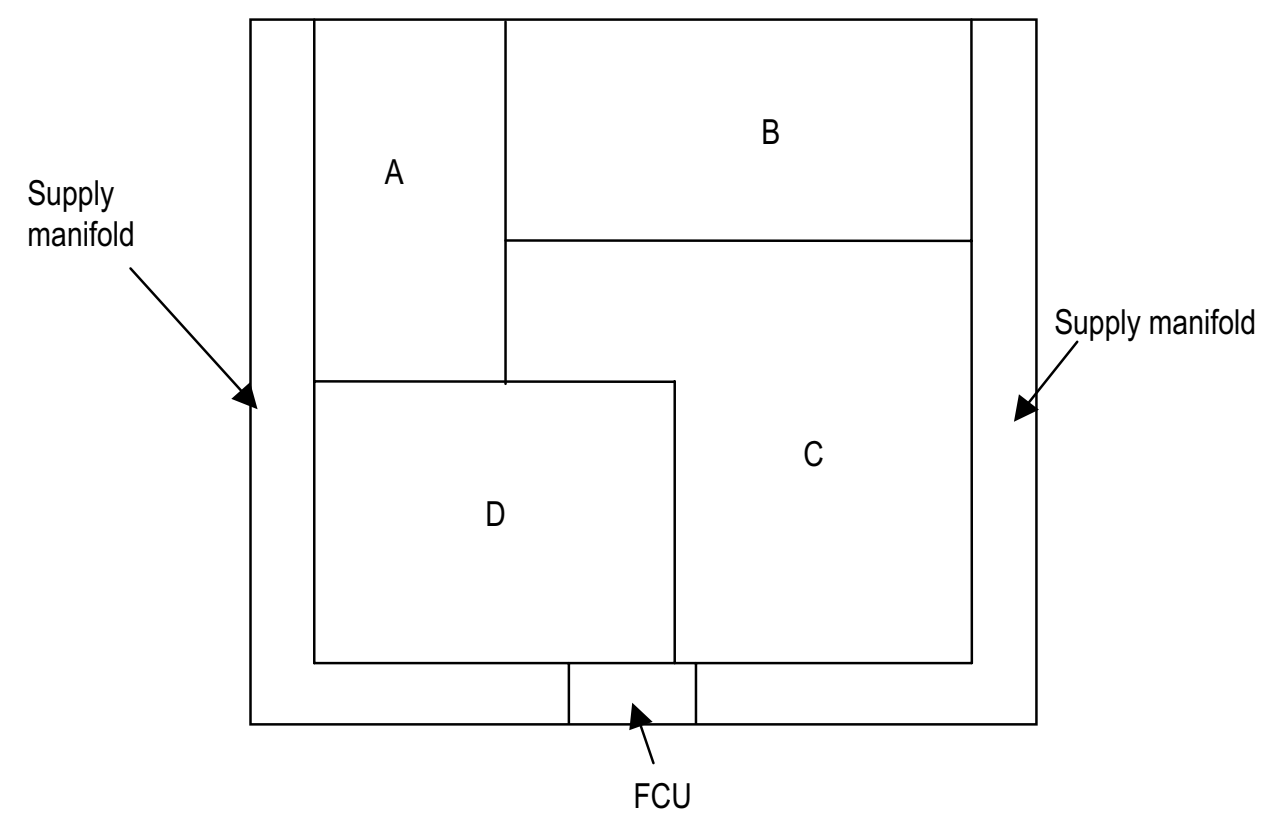

Figure 2: Layout of Pod Y 
Two data loggers (Campbell Scientific CR10X) and a combination of calibrated Type $T$ thermocouples and thermistors were used to record 24 temperatures at various points in Pod Y. The second period of monitoring was AugustDecember 2003. In this period, one panel in the same pod in the northwest corner on each level was instrumented e.g. $X_{3}$ (Fig. 1). Four data loggers recorded temperatures at 47 positions in the panels, rooms and associated areas.

\section{AIRFLOW MEASUREMENTS}

Airflow from the outlet holes in five pods was measured at various times during 2003 using a 100-mm diameter vane anemometer (Airflow AV2). Table 3 summarizes the measurements made from the 15 holes in Pod Y. The average flow rate was found to be $8.5 \mathrm{l} / \mathrm{s}$ or 1.9 air changes per hour, which is $5 \%$ below the design value. The flow from the holes, however, was very uneven, despite the use of simple baffles to restrict the flow at some holes. Flow rates varied from zero from two holes (A1 and B2) to $22.4 \mathrm{l} / \mathrm{s}$ from hole $\mathrm{C} 1$ i.e. $264 \%$ higher than the average. A similar variation was found in the other four pods, where outlet air flow rates were measured. While this variation has minimal effect in open plan offices, the effect can be severe in enclosed offices as in Pod Y. The higher exit air velocities can also cause unacceptable noise and draughts. For example, in two offices in Pod Z (Fig. 1), the occupants had blocked off the outlet holes above their desks. Air exchange rates in Pods $X_{1}, X_{2}, X_{3}$ and $Z$ were found to 2.2, 2.6, 2.2 and 2.5 respectively, i.e. all slightly higher than the design value.

\begin{tabular}{|c|c|c|c|c|c|c|c|c|c|c|c|c|c|c|c|}
\hline & \multicolumn{3}{|c|}{ Room A } & \multicolumn{4}{|c|}{ Room B } & \multicolumn{5}{|c|}{ Room C } & \multicolumn{3}{|c|}{ Room D } \\
\hline Hole No & A1 & A2 & A3 & B1 & B2 & B3 & B4 & $\mathrm{C} 1$ & $\mathrm{C} 2$ & $\mathrm{C} 3$ & C4 & $\mathrm{C} 5$ & D1 & D2 & D3 \\
\hline Flow $\left(\mathrm{I} \mathrm{s}^{-1}\right)$ & 0 & 3.9 & 8.3 & 16.9 & 0 & 12.3 & 13.7 & 22.4 & 9.5 & 8.0 & 3.1 & 7.5 & 7.4 & 3.2 & 10.8 \\
\hline
\end{tabular}

Table 3: Airflow rates measured at outlet holes in Pod $Y$

\section{THERMAL PERFORMANCE}

The temperature and airflow measurements have been used to investigate the performance of the FES system and its influence on room temperatures from a number of perspectives. The results of these investigations, together with some analysis of the time spent in various modes of operation, the electricity consumption data, a user survey and some comments about performance when heating are presented below.

\section{Radiant Cooling Effect}

A FES system is a potential source of about $1.5^{\circ} \mathrm{C}$ of radiant cooling (Bunn 1998). Fig. 3 compares the ceiling surface temperature and the room air temperature at 1.1 metres above floor in Space C. On the day (17/1/2003), the maximum ambient air temperature was approximately $28.4^{\circ} \mathrm{C}$. The average difference between the air temperature and surface temperatures during working hours was $1.0^{\circ} \mathrm{C}$, indicating that room occupants benefited from a radiant cooling effect. During the occupied hours the core and surface temperatures of the FES were almost identical but at other times the surface of the panels responded more quickly to the fall in office air temperature.

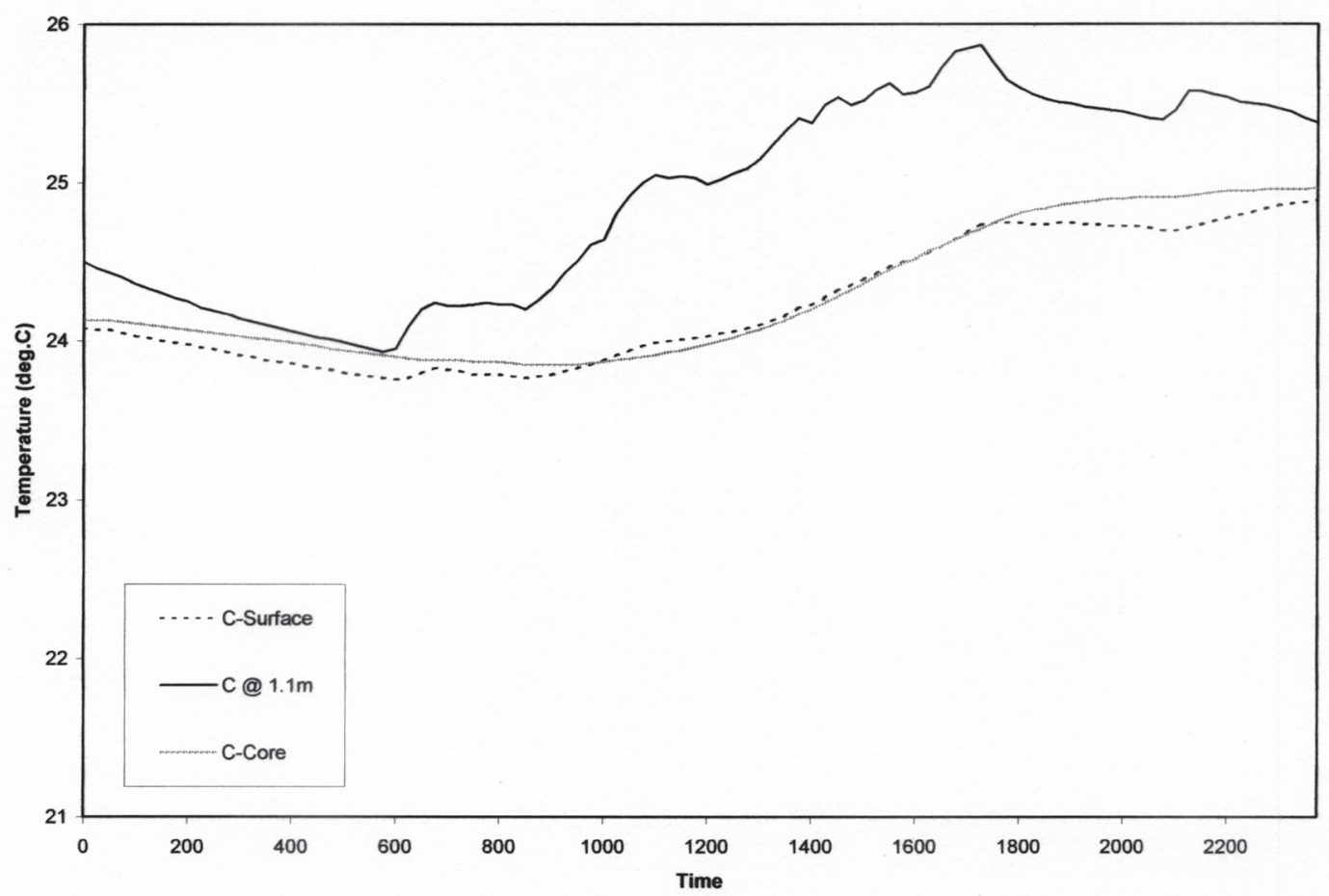

Figure 3: Comparison of ceiling surface and core temperatures with air temperature 
Cooling Power

The net cooling power attributable to a FES system is the sum of the radiant and natural convective components and any cooling effect from the incoming air. The system has been designed so that cool air may be delivered to the occupied spaces during the day, if conditions demand (Mode 4). On the same day (17/1/2003), the system entered Mode 4 at approximately $10: 15$ and continued in this state until approximately $21: 15$. Cooled air was delivered from the FCU at an average temperature of $21.8^{\circ} \mathrm{C}$ during this time. Fig. 4 shows the temperature of the air delivered from the monitored outlet holes in Pod $\mathrm{Y}$, as well as the FCU delivery temperature. The impact of zero airflow from outlets B2 and A1 is evident, the air temperature at these locations being identical to the general air temperature of the particular office. The temperatures of the air delivered from the other outlet holes reflect the temperature of the air delivered by the FCU, to a greater or lesser extent, depending on their position. The air coming from the outlet holes closest to the supply manifolds and FCU e.g. C1 exhibit the greatest benefit of the chilled FCU air. The variation in outlet air temperatures was caused by multiple outlets holes and uneven airflows.

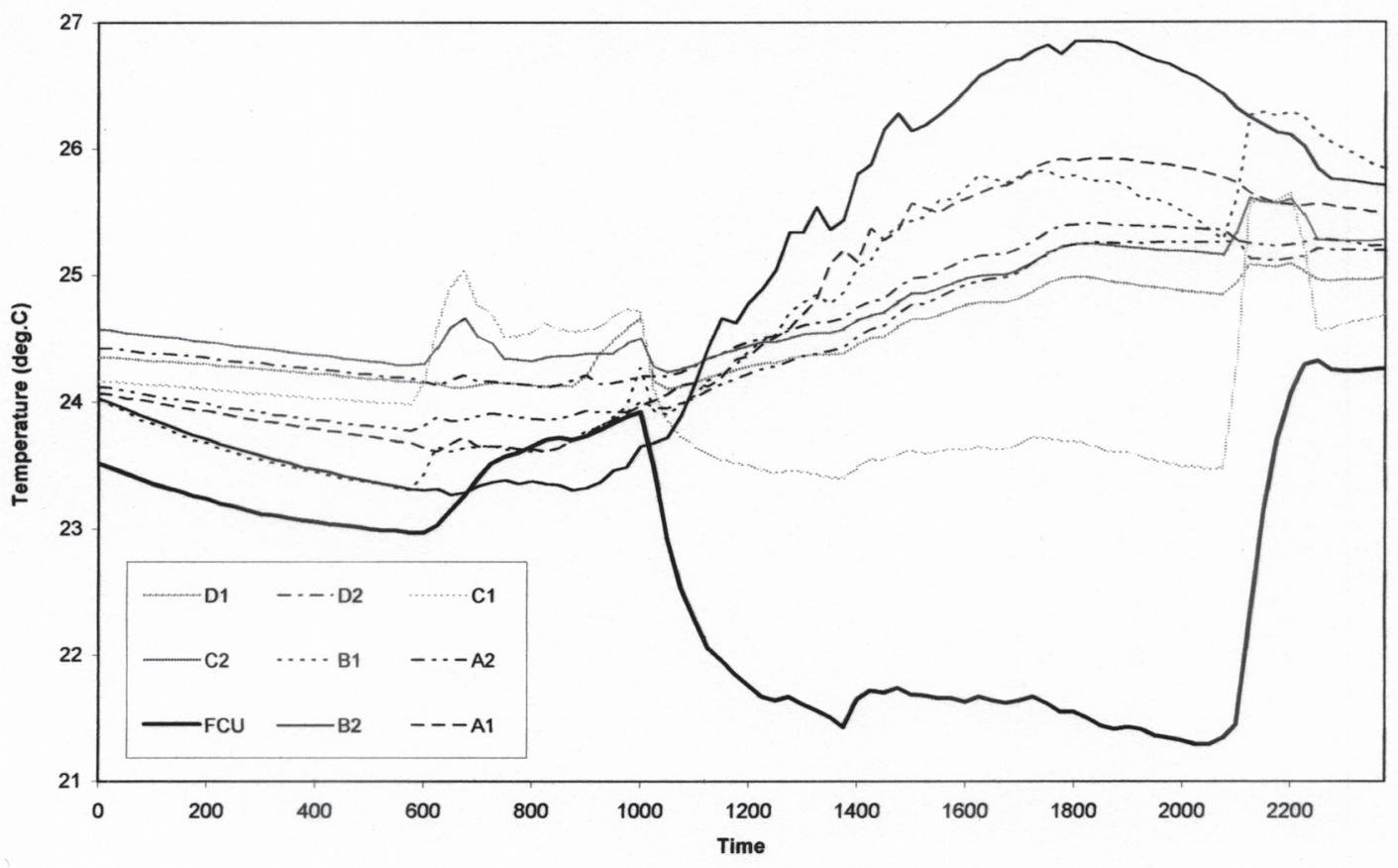

Figure 4: Variations in room outlet air temperatures during Mode 4

\begin{tabular}{|l|r|r|r|r|r|r|r|r|}
\hline \multicolumn{1}{|c|}{ Hole No } & \multicolumn{1}{c|}{ A1 } & \multicolumn{1}{c|}{ A2 } & \multicolumn{1}{c|}{ B1 } & \multicolumn{1}{c|}{ B2 } & \multicolumn{1}{c|}{ C1 } & \multicolumn{1}{c|}{ C2 } & \multicolumn{1}{c|}{ D1 } & \multicolumn{1}{c|}{ D2 } \\
\hline Av outlet air temperature $\left({ }^{\circ} \mathrm{C}\right)$ & 25.2 & 24.7 & 25.1 & 25.8 & 23.6 & 24.8 & 24.6 & 24.9 \\
\hline Outlet air velocity $\left(\mathrm{m} \mathrm{s}^{-1}\right)$ & 0 & 0.50 & 2.15 & 0 & 2.85 & 1.21 & 0.94 & 0.41 \\
\hline Net delivered cooling energy $(\mathrm{kJ})$ & 0 & 92 & 851 & 0 & 1928 & 284 & 292 & -23 \\
\hline
\end{tabular}

Table 4: Air temperatures, velocities and energy delivered in Mode 4 over an 11-hour period

Table 4 shows the average outlet air temperature, air velocity and the net cooling energy delivered from each of the instrumented outlet holes, based on the average room temperature during the same period. The unevenness of delivered cooling is due principally to the uneven airflow. The natural convection effect was calculated assuming an air velocity of $0.5 \mathrm{~ms}^{-1}(\mathrm{AIRAH}, 1989)$. The average cooling energy power available during working hours on that day for each space was thus calculated (Table 5). Because the differences between the air and surface temperatures are small, doubling the assumed air velocity due to natural convection results only in a ten percent increase in total cooling power.

\begin{tabular}{|l|r|r|r|r|}
\hline \multicolumn{1}{|c|}{ Component } & \multicolumn{1}{c|}{ Room A } & \multicolumn{1}{c|}{ Room B } & Room C & Room D \\
\hline Inlet air $\left(\mathrm{W} \mathrm{m}^{-2}\right)$ & 0 & 8.2 & 12.2 & 1.7 \\
\hline Radiant effect $\left(\mathrm{W} \mathrm{m}^{-2}\right)$ & 0.6 & 4.4 & 4.9 & 1.5 \\
\hline Convection (natural) $\left(\mathrm{W} \mathrm{m}^{-2}\right)$ & 0.8 & 7.1 & 7.9 & 2.4 \\
\hline Total cooling power $\left(\mathrm{W} \mathrm{m}^{-2}\right)$ & 1.4 & 19.7 & 25.0 & 5.6 \\
\hline
\end{tabular}

Table 5: Calculated total cooling power in Pod $Y$ on typical summer day 
Willis and Wilkins (1993) report cooling power rates of 10-16 W $\mathrm{m}^{-2}$ for a FES system determined under experimental conditions. Individual rooms will have different cooling loads depending on their location, equipment and occupancy levels, but the large differences in cooling power illustrate the problem created by the current design of full partition offices, multiple air outlets per panel and unbalanced air distribution.
Panel Temperatures

One of the design objectives of the heating and cooling system was to maintain the FES in the temperature range of $18-20^{\circ} \mathrm{C}$.

Fig. 5 shows the core temperatures in monitored rooms on Level 3 in January, August and December. Table 6 provides a summary of the average, maximum and minimum panel core temperatures in those months.

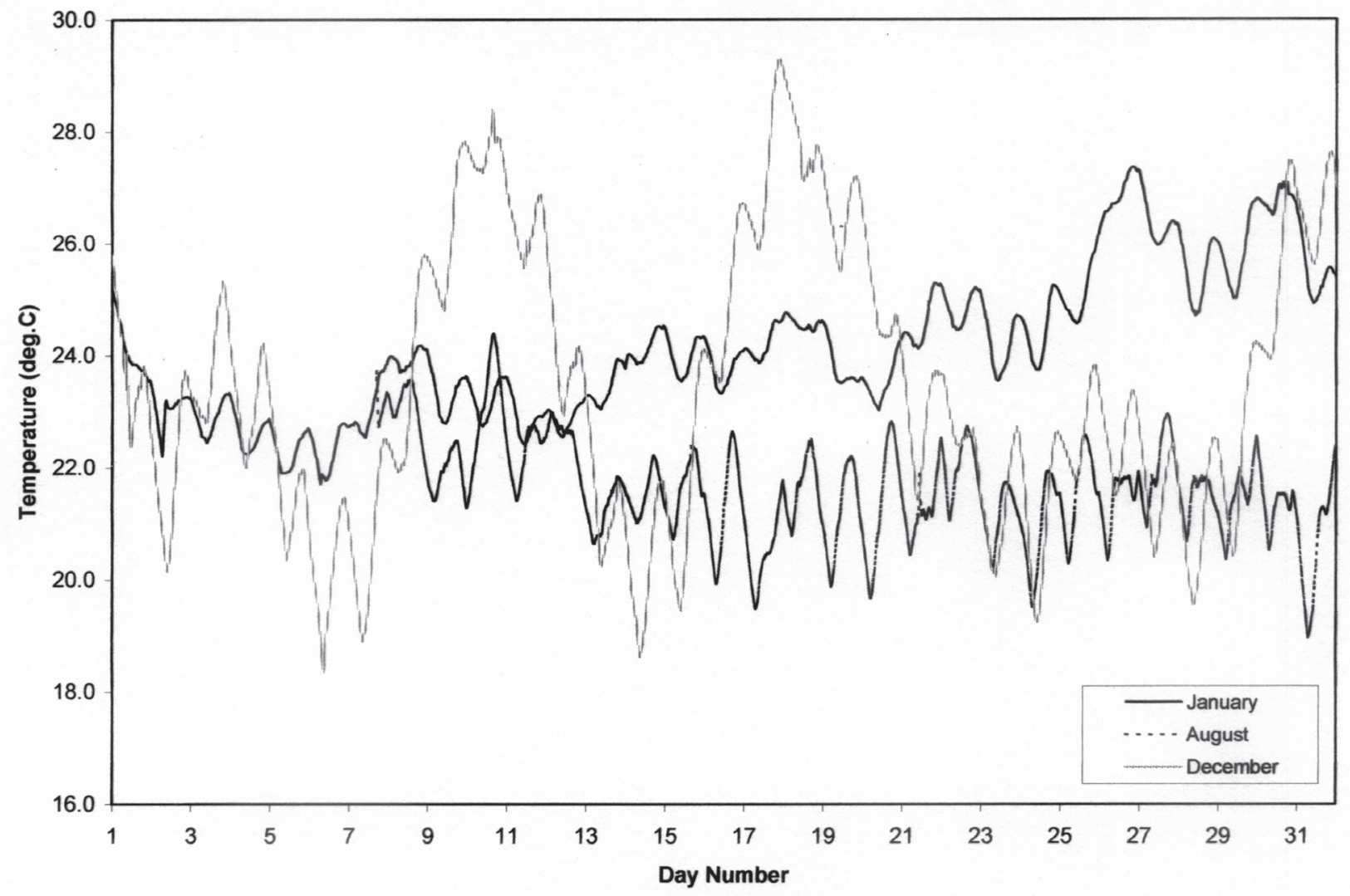

Figure 5: Average core temperatures on Level 3 in January, August and December 2003

\begin{tabular}{|l|c|c|c|}
\hline \multicolumn{1}{|c|}{ Measurement } & January & $\begin{array}{c}\text { August } \\
(25 \text { days })\end{array}$ & December \\
\hline Average Core Temp $\left({ }^{\circ} \mathrm{C}\right)$ & 24.1 & 21.6 & 23.5 \\
\hline Max Core Temp $\left(^{\circ} \mathrm{C}\right)$ & 27.4 & 24.4 & 29.3 \\
\hline Min Core Temp $\left(^{\circ} \mathrm{C}\right)$ & 21.7 & 19.0 & 18.4 \\
\hline
\end{tabular}

Table 6: Summary of core temperatures in January, August and December 2003

Although the data for the first seven days of August is unavailable, the measurements show that the panels remained above the upper design level for $96 \%$ of the rest of the month, indicating that more heating energy was used than necessary. In January and December, the FES core temperatures were above the design level for almost all of the time. A number of factors contributed to this. In January, night purging (Mode 6) could not be achieved because the external louvres did not open and Mode 5 operated for only 10 minutes per night due to a software error. Although some night purging was possible in December, software problems inactivated all modes for between five and nine hours per night. In addition, there were problems with the chiller operation, preventing the day cooling (Mode 4). This also occurred in late January, when the chiller failed to operate for the final eight days of the month. The FES temperature can be seen to rise at this time. The high peaks in FES temperature in December are also attributed to failures in chiller operation and the low troughs due to the failure of heating modes at night because of the software error.

\section{Room Temperatures}

The month of December in 2003 was the hottest in Melbourne since 1873. It therefore provided an ideal test for the building and its cooling system. Table 7 summarizes the temperatures 
measured at 1.1 metres above floor level on the north-west end of the building on each of its three levels during December. Also shown are the number and percentage of working hours i.e. 09:00-17:00 that the monitored spaces exceeded the design maximum. In the design stage of the building, it was acknowledged that the temperature of the offices would sometimes exceed $28^{\circ} \mathrm{C}$ during working hours. Simulations indicated that this would occur for 23 hours $(1.2 \%)$ of the occupied hours and this was thought to be acceptable (Fuller and Luther, 2002). Measurements show that the design target was not achieved.

\begin{tabular}{|l|r|r|r|}
\hline & \multicolumn{1}{|c|}{ Level 1 } & \multicolumn{1}{c|}{ Level 2 } & \multicolumn{1}{c|}{ Level 3 } \\
\hline Average temperature $\left({ }^{\circ} \mathrm{C}\right)$ & 24.8 & 25.1 & 24.5 \\
\hline Maximum temperature $\left({ }^{\circ} \mathrm{C}\right)$ & 29.8 & 30.1 & 31.1 \\
\hline Minimum temperature $\left({ }^{\circ} \mathrm{C}\right)$ & 20.3 & 20.3 & 18.8 \\
\hline No of working hours $>28^{\circ} \mathrm{C}$ & 45 & 101 & 99 \\
\hline$\%$ of working hours $>28^{\circ} \mathrm{C}$ & $2 \%$ & $5 \%$ & $5 \%$ \\
\hline
\end{tabular}

Table 7: Summary of monitored room air temperatures at 1.1 metres above floor level during December 2003

\section{Storage Utilization}

The outlet hole arrangement used in this FES system impacts on storage utilization. Only $82 \%$ of the practical panel length is used because most of the fifth core is unused. Even if the air leaving each of the three holes were evenly balanced by flow adjusters, one third of the air would pass through only $20 \%$ of the panel. Half of the remaining air would pass through only $30 \%$ of the panel and only one third would pass through $82 \%$ of the panel. Research has confirmed that FES systems are most effective when the path length is a maximum prior to discharging the air (Barton et al., 2002; Winwood et al., 1997b). The discharge of a significant proportion of the tempered air at the first and second holes reduces the potential to change panel temperatures significantly. Since the heat transfer rate between the concrete and the air is a function of its velocity, the multiple holes and constant diameter ducts also result in falling velocities and uneven heat transfer.

\section{Day Cooling}

In Mode 4, chilled air is forced through the panels during the day, if the outside temperature rises above $26^{\circ} \mathrm{C}$. The inclusion of this mode presumes that internal air and panel temperatures will also be rising and that some cooling is required to maintain the room temperature within design limits. Figs. 3 and 4 show the effects on the panel core, surface and room temperatures of supplying chilled air through the panels during the day. Although the air delivered into Room $\mathrm{C}$ is below the room air temperature, the difference is only about $1.2^{\circ} \mathrm{C}$. The latter continues to rise throughout the day until approximately 17:15 hour, when the outside ambient air temperature begins to decline and this is reflected in both the internal room temperature and the panel surface temperature. The chilled air only provides a marginal cooling effect to the room, and is unable to prevent the temperatures of the room air or the panel from rising.

\section{Night Cooling}

The night cooling mode has been included in the event that both the panel temperature and ambient temperatures are greater than $20^{\circ} \mathrm{C}$ at night and is designed to operate until the panel reaches $18^{\circ} \mathrm{C}$. In the first period of experimentation, the temperature of the chilled air delivered from the monitored FCU on Level 3 was always between $20^{\circ} \mathrm{C}$ and $22^{\circ} \mathrm{C}$, indicating that cooling of the concrete panels to the design point of $18^{\circ} \mathrm{C}$ could never be achieved. Even when the panel temperature rises above the current FCU delivery temperature to, say $27^{\circ} \mathrm{C}$, as in Fig. 6 , it will require about 25 hours of operation to cool the concrete to $22^{\circ} \mathrm{C}$. Currently the length of period for the operation of Mode 5 is limited to ten hours (20:00-08:00).

\section{Night Purging}

In early summer months of 2003 (January and February), the effectiveness of the night purging mode (Mode 6) could not be assessed because the louvres on the north side AHU did not open to admit ambient air. Problems with the software were experienced later in the year (October-December) when night purging was once again required. As a result, it severely limited the time over which night purging occurred. Only a limited indication of the effectiveness of the night purging mode could be obtained from the recorded data. Fig. 6 shows the effect of the night purging mode on the monitored panel on Level 2 over a 33-hour period, beginning at midnight on $12^{\text {th }}$ December. 


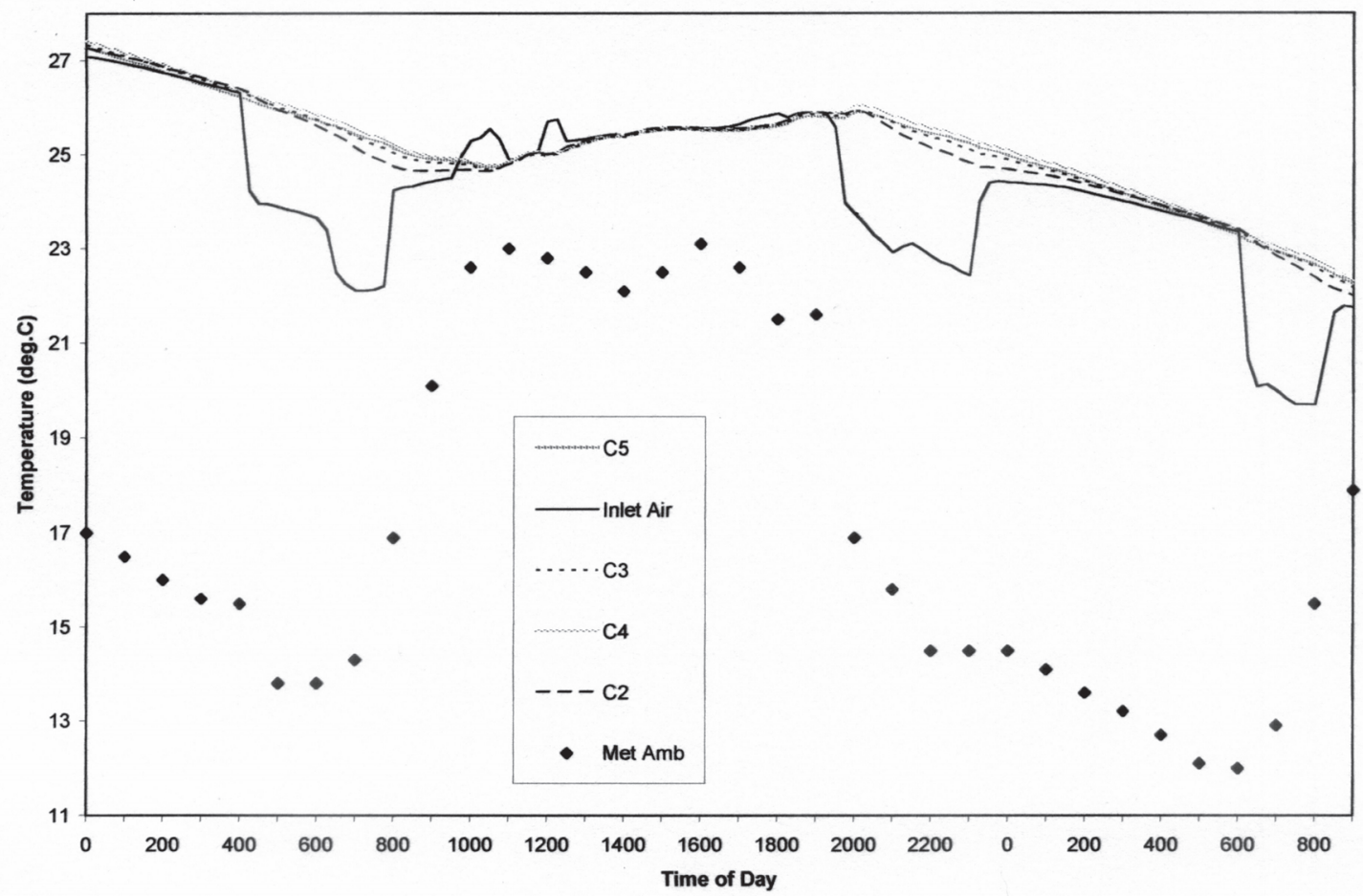

Figure 6: Effectiveness of night purging

Although the core of the concrete panel is at $27^{\circ} \mathrm{C}$ and the ambient temperature is ten degrees lower, no purging occurs because the system is (erroneously) in shutdown mode (Mode 8). At hour 4:00, purging commences and continues for four hours until hour 8:00. A similar pattern occurs on the second night, but in this case, purging initially begins at hour 18:00 and continues until 23:00, when the purging mode is again overridden and the system goes into the shutdown mode. Night purging resumes for two hours (6:00-8:00) on the following morning. Despite the limited time in the night purging mode, some evidence of its effect is reflected in the decline the temperature of the first monitored section of the panel core (C2) on both nights. When there is no night purging, the temperature of this core of the panel is identical to the remaining monitored cores. The negative impact of discharging one third of the ambient air through the first outlet hole before the full cooling potential of the air has been exploited is evident.

Fig. 6, however, reveals a more serious problem, which is limiting the potential of the night purging mode. The inlet air temperature is, on average, nearly $8^{\circ} \mathrm{C}$ higher than the outside ambient temperature during the hours of purging, and indicates that the ambient air has gained energy as it passes through the central and pod ducting. As a result, when it is finally forced through the concrete panels, its potential to remove energy and cool the ceiling is greatly reduced. A similar problem was reported in the first UK FES building, where heat gains reduced available cooling from the ambient air by $7.5^{\circ} \mathrm{C}$ (Winwood et al., 1997d). These gains were attributed to insufficient duct insulation, fan and plant room energy gains.

\section{Control Strategy}

The building management system (BMS) data was analysed to determine the number of times the individual modes of operation were called every month during 2003 and the difference between these hours and the actual number of hours in each month (Table 8). Various positive and negative aspects of the existing control software have been identified from the data.

\begin{tabular}{|c|c|c|c|c|c|c|c|c|c|}
\hline Month & Mode 1 & Mode 2 & Mode 3 & Mode 4 & Mode 5 & Mode 6 & Mode 7 & Mode 8 & Diff \\
\hline Jan & 76 & 133 & 307 & 224 & 0 & 189 & 0 & 5 & +190 \\
\hline Feb & 48 & 144 & 329 & 159 & 0 & 246 & 0 & 5 & +259 \\
\hline Mar & 114 & 237 & 309 & 99 & 0 & 217 & 0 & 5 & +237 \\
\hline Apr & 284 & 201 & 262 & 88 & 0 & 239 & 0 & 5 & +359 \\
\hline May & 447 & 229 & 131 & 2 & 0 & 0 & 0 & 15 & +80 \\
\hline Jun & 602 & 149 & 26 & 0 & 0 & 0 & 0 & 18 & +75 \\
\hline Jul & 642 & 93 & 8 & 0 & 0 & 0 & 0 & 5 & +4 \\
\hline Aug & 493 & 161 & 16 & 0 & 0 & 0 & 11 & 115 & +52 \\
\hline Sep & 544 & 68 & 28 & 0 & 0 & 0 & 0 & 155 & +75 \\
\hline Oct & 550 & 85 & 219 & 12 & 0 & 0 & 0 & 178 & +300 \\
\hline Nov & 355 & 122 & 161 & 112 & 34 & 58 & 0 & 175 & +300 \\
\hline Dec & 120 & 136 & 259 & 243 & 121 & 267 & 0 & 175 & +577 \\
\hline
\end{tabular}

Table 8: Hours per month recorded in operating modes during 2003 
The extent to which conflicting control conditions could exist at any one time can be seen by the number of hours in excess of the maximum possible in any given month. In December, for example, it has been established that as many as three modes were called at any one time. Changes to the software in early August appear to have caused the system to enter the shutdown mode ${ }^{1}$ (Mode 8) for much of each night, over-riding all other modes.

The hours recorded for the main heating mode (Mode 1) indicate how often the boiler was ready to supply heat rather than the actual hours of boiler operation. This potential overdemand of the heating system occurs because the control system is driven by ambient rather than panel temperatures. Analysis of the inlet duct air temperature data showed that in spring and summer months, the number of hours when heat was actually delivered is only a fraction of the hours in which the boiler was prepared to supply.

Mode 2 shows the value of atrium heating, particularly in the spring and autumn months. The heat delivered in this mode reduced the need to operate the boiler. Mode 3 and 6 are the only modes when fresh air is actively drawn into the building. The data and the comments from occupants (see Occupant Survey) indicate that fresh air delivery is probably inadequate, particularly in winter, when Mode 6 is not used. Between May and September, assuming all hours of Mode 3 operation were during office hours, the windows were open for only $24 \%$ of the occupied hours. At other times, the atrium air was used for ventilation purposes. Mode 7, the warm-up mode, included to prevent occupants from exposure to cold concrete surfaces i.e. below $18^{\circ} \mathrm{C}$, appears to be a redundant mode. It was only required for 11 hours in August.

\section{Energy consumption}

The energy use associated with the FES system includes the gas consumption for the heating system and the electricity used by the chiller, pumps and fans. Unfortunately no gas consumption meter has been installed to date and no estimate of heating requirements can be made accurately. Electricity consumption for all components of the FES during 2003 was $27.6 \mathrm{kWh} \mathrm{m}^{-2}$. Although this figure is low compared to equivalent commercial buildings in Melbourne, any comparison must be treated cautiously. Inclusion of gas consumption will increase energy consumption but correction of the many problems e.g. night purging may decrease energy use. Other factors will also have contributed to the low energy consumption, particularly the wide internal temperature range tolerated in Building $\mathrm{T}$.

\section{Occupant Survey}

In March 2003, the occupants were surveyed about the lighting, ventilation and comfort levels in the building. In general, the questionnaire was designed to determine problems, rather than positive views of the building. Assuming the absence of a complaint indicated satisfaction, only one third of occupants were satisfied with the air quality. Complaints about stuffiness and smells were received from $66 \%$ of respondents. Analysis of the mode data suggested that ventilation levels were inadequate in winter, but the users' responses also indicate insufficient fresh air at other times of the year. Fifty percent of occupants responded with unfavourable comments about excess temperatures in their workspaces. Given the problems that occurred with the control software and mechanical hardware in the first summer months, this was not surprising. Most users thought the light levels in the building ranged from good to excellent and only $24 \%$ believed the levels were poor.

\section{Heating}

The primary concern of commercial building designers in Australia is usually to reduce peak cooling loads and achieve reasonable comfort levels in summer. Heating is not usually viewed as problem in most Australian climates and this was the experience in Building T during the winter months. Panel temperatures in August were above the design level for almost the entire month with an average core temperature of $21.6^{\circ} \mathrm{C}$ (Table 6). This temperature is within the $20-22^{\circ} \mathrm{C}$ range sought by European users (Winwood et al., 1997d). Since only one user complained that their office was sometimes too cold in the morning, it appears that the FES system performed satisfactorily in winter.

\section{CONCLUSIONS}

The operation of the FES system in Building T has been marred by a variety of problems, which include mechanical breakdowns and control software errors. The building is a high-mass building with insulated concrete walls on east and west ends. This, together with other low energy features, has contributed to the relatively stable thermal environment and reduced energy use. Occupant comfort has not been satisfactory in the summer months, with some occupants experiencing temperatures above $28^{\circ} \mathrm{C}$ for $5 \%$ of their working hours. Fresh air requirements appear to have been too low. As a result, it is not yet possible to say with certainty whether FES systems are able to reduce energy consumption while maintaining occupant comfort in the southern Australian climate.

There are a number of design and installation problems that have been shown to be adversely affecting the FES performance. These include too many outlet holes, resulting in an under-utilization of the full storage potential of FES and unbalanced delivery of air to the occupied spaces. The current control system is based primarily on external ambient temperature, rather than FES temperature and so underestimates the thermal storage capacity of the building and over-estimates the need for heating and cooling. The heat gain to ambient air as it passes through the ductwork in the night purging mode is considerable and this may compromise the effectiveness of this strategy, which is central to the efficient operation of a FES system in a warm climate. 


\section{ACKNOWLEDGEMENTS}

Other Deakin staff and students are acknowledged for their contribution to this research, including Sam Wishart, Joseph Cheung, Peter Taylor, Malcolm Munro and Martin Butcher. The assistance of Jonathan Wood from Umow Lai Pty Ltd is also acknowledged.

\section{REFERENCES}

AIRAH (1989). Handbook. The Australian Institute of Refrigeration Air Conditioning and Heating (Inc.)

Barton, P., Beggs, C.B. and Sleigh, P.A. (2002). A theoretical study of the thermal performance of the Termodeck hollow core slab system. Applied Thermal Engineering, 22, 13, 1485-1499.

Bunn, R. (1998). Cool desking. Building Services Journal, Oct., 16-20.

Cohen, R. and Bunn, R. (2001). Learning from Probe. Building Services Journal, May, 63-65.

Fuller, R.J. and Luther, M.B (2002). Thermal simulation of an Australian university building. Building Research and Information, 30, 4, 255-263.

Probe Team (1998). Probe 14: Elizabeth Fry Building. Building Services Journal, April, 37-42.

Property Council of Australia (PCA) (1997). Victorian Energy Use Survey 1996. Property Council of Australia, Victorian Division, 31 pages.

Willis, S. and Wilkins, J. (1993). Mass appeal. Building Services, January, 25-27.

Winwood, R. (1997). Termodeck: In-Use Performance. Building Services Journal, Nov., 47-48.

Winwood, R., Benstead, R. and Edwards, R. (1997a). Advanced fabric energy storage I: Review. Building Services Engineering Research Technology, 18, 1, 1-6.

Winwood, R., Benstead, R. and Edwards, R. (1997b). Advanced fabric energy storage II: Modelling. Building Services Engineering Research Technology, 18, 1, 7-16.

Winwood, R., Benstead, R. and Edwards, R. (1997d). Advanced fabric energy storage IV: Experimental monitoring. Building Services Engineering Research Technology, 18, 1, 25-30. 